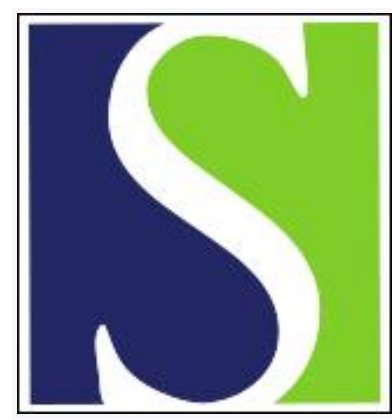

Scand J Work Environ Health 2001;27(4):258-267

https://doi.org/10.5271/sjweh.613

Issue date: Aug 2001

Psychosocial work characteristics and psychological strain in relation to low-back pain

by Hoogendoorn WE, Bongers PM, de Vet HCW, Houtman ILD, Ariëns GAM, van Mechelen W, Bouter LM

Affiliation: Leids Universitair Medisch Centrum, Medische Besliskunde, K6-R, Postbus 9600, 2300 RC Leiden, Netherlands. W.E.Hoogendoorn@lumc.nl

Refers to the following texts of the Journal: 1997;23(4):243-256 1999;25(6):616-624 1999;25 suppl 4:19-24 1998;24(6):465-472 $1997 ; 23(2): 121-129$

The following articles refer to this text: $2002 ; 28(4): 222-231$; 2003;29(6):431-440; 2004;30(1):47-55; 2004;30(1):56-63; 2004;30(6):459-467; 2012;38(3):282-290

Key terms: industrial psychology; job satisfaction; low-back pain; prospective cohort study; psychological strain; psychological stress; psychosocial work characteristics; risk factor; social support

This article in PubMed: www.ncbi.nlm.nih.gov/pubmed/11560340

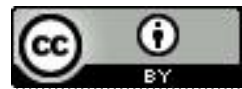




\title{
Psychosocial work characteristics and psychological strain in relation to low-back pain
}

\author{
by Wilhelmina E Hoogendoorn, PhD, ${ }^{1,2,3,4}$ Paulien M Bongers, PhD, ${ }^{1}$ Henrica CW de Vet, PhD, ${ }^{2}$ \\ Irene LD Houtman, PhD, ${ }^{1}$ Geertje AM Ariëns, PhD, ${ }^{1,2,3}$ Willem van Mechelen, PhD, ${ }^{2,3}$ Lex M Bouter, PhD ${ }^{2}$
}

\begin{abstract}
Hoogendoorn WE, Bongers PM, de Vet HCW, Houtman ILD, Ariëns GAM, van Mechelen W, Bouter LM. Psychosocial work characteristics and psychological strain in relation to low-back pain. Scand J Work Environ Health 2001;27(4):258-267.
\end{abstract}

Objectives This study investigated the relationship between psychosocial work characteristics and low-back pain and the potential intermediate role of psychological strain variables in this relationship.

Methods The research was part of a prospective cohort study of risk factors for musculoskeletal symptoms. The study population consisted of 861 workers from 34 companies in The Netherlands who had no low-back pain at baseline and for whom data on the occurrence of low-back pain were obtained with annual questionnaires during a 3-year follow-up period. Information on psychosocial work characteristics and psychological strain variables was collected using a questionnaire at baseline. Cases of low-back pain were defined as workers who reported, in at least one of the annual follow-up questionnaires, that they had had regular or prolonged low-back pain in the previous 12 months.

Results After adjustment for individual factors and quantified physical load at work, nonsignificant relative risks ranging from 1.3 to 1.6 were observed for high quantitative job demands, high conflicting demands, low supervisory support, and low co-worker support. Decision authority and skill discretion showed no relationship with low-back pain. In general, the estimated relative risks for the psychosocial work characteristics were scarcely influenced by additional adjustment for job satisfaction, emotional exhaustion, and sleeping difficulties. Conclusions It can be concluded that low social support, from either supervisors or co-workers, appears to be a risk factor for low-back pain. Some indications of a relationship between high quantitative job demands and high conflicting demands and low-back pain were also found. Little evidence was found for an intermediate role for the psychological strain variables under study.

Key terms industrial psychology, job satisfaction, prospective cohort study, psychological stress, risk factors, social support.

The study of psychosocial work characteristics has become an important aspect of epidemiologic studies on musculoskeletal symptoms among workers. Recently, several reviews of the literature on the relationship between psychosocial work characteristics and low-back pain have been conducted (1-5). According to these reviews, it seems that a relationship exists between psychosocial work characteristics, in general, and the occurrence of low-back pain, but the role of specific psy- chosocial work characteristics and the causality of the observed relationships is not yet clear $(4,5)$.

Several explanations have been given for the relationship between psychosocial work characteristics and musculoskeletal symptoms. One of the suggestions is that the association is based on confounding by the effect of physical factors at work $(1,6,7)$. From this perspective, an important shortcoming of most previous studies on the risk of specific psychosocial work

TNO Work and Employment, Hoofddorp, The Netherlands.

Institute for Research in Extramural Medicine, Vrije Universiteit, Medical Center, Amsterdam, The Netherlands. Department of Social Medicine, Vrije Universiteit, Medical Center, Amsterdam, The Netherlands.

Current Affiliation: Leiden University Medical Center, Department of Medical Decision Making, Leiden, The Netherlands.

Reprints requests to: Lisette Hoogendoorn, Leids Universitair Medisch Centrum, Medische Besliskunde, K6-R, Postbus 9600, 2300 RC Leiden, The Netherlands. [E-mail: W.E.Hoogendoorn@ @lumc.nl] 
characteristics is that, in these studies, insufficient adjustment was made for the physical load at work. Another hypothesis is that psychosocial work characteristics increase psychological strain, such as emotional exhaustion (8), which, in turn, may increase muscular tension or hormonal excretion. In the long term, the result could be organic changes and the development or aggravation of musculoskeletal symptoms, or the level of pain perception may be lowered and cause increased symptom reporting $(1,6,7,9,10)$. This latter hypothesis implies that psychological strain would be an intermediate variable in the relationship between psychosocial work characteristics and the occurrence of low-back pain. In light of this hypothesis, not only emotional exhaustion (8) and sleeping difficulties (11), but also job satisfaction, which is often grouped under the heading of psychosocial work characteristics in research on lowback pain, can be regarded as a psychological strain variable $(12,13)$. No epidemiologic study has been identified in which this possibility has been investigated.

The main purpose of our analyses was to investigate the relationship between the psychosocial work characteristics of quantitative job demands, conflicting demands, decision authority, skill discretion, supervisory support, and co-worker support and the occurrence of low-back pain, taking into account the potential confounding effect of individual factors and physical load at work. An additional objective was to study the potential intermediate role of psychological strain in the relationship between psychosocial work characteristics and low-back pain. The analyses were based on data from a project called the Study on Musculoskeletal Disorders, Absenteeism, Stress, and Health (SMASH), which was a prospective cohort study among a working population initiated to identify risk factors for musculoskeletal disorders. The results concerning the relationship between physical load at work and low-back pain have been reported elsewhere (14).

\section{Subjects and methods}

Workers were recruited from 34 companies located throughout The Netherlands. A prerequisite for companies to participate was that no major reorganization had been planned for the next 3 years and that the turnover rate of the workforce was lower than $15 \%$. Furthermore, the companies were asked to select workers who had been employed in their current job for at least 1 year and who were working 24 hours a week or more. Workers in blue-collar jobs, as well as workers in white-collar jobs and caring professions, were included in the study.
The baseline measurements were carried out between March 1994 and March 1995 and consisted of the following three aspects: (i) a self-administered questionnaire, (ii) a quantitative assessment of the physical load at the workplace, and (iii) a physical examination focused on the assessment of the functional capacity of the workers. There was a 3-year follow-up period. Each year the occurrence of work changes and low-back pain was assessed by means of a postal questionnaire.

At the beginning of the study, $1789(87 \%)$ of the 2064 workers invited to participate completed the questionnaire, 1738 of whom were eligible for participation in the study on risk factors for low-back pain (14). For the longitudinal analysis described in this paper, a subcohort of 1192 workers with no low-back pain at the beginning of the study was identified. It consisted of workers who, at the beginning of the study, had not had regular or prolonged low-back pain in the previous 12 months.

\section{Data collection}

All risk factors included in the analyses were measured at the beginning of the study. Psychosocial work characteristics were measured by means of a Dutch version of Karasek's job content questionnaire (15), and they concerned the dimensions of quantitative job demands, decision authority, skill discretion, supervisory support, and co-worker support, as determined in the demandcontrol-support model developed by Karasek and his colleagues (16-18). The constructed scales were sum scores of the individual items within the dimension at issue. The response options for the individual items ranged from 1 (strongly disagree) to 4 (strongly agree). Conflicting demands and job security were both assessed on the basis of 1 single item from the job content questionnaire (15). In the analyses, job security was only considered as a potential confounder. Potential intermediate psychological strain variables were also assessed by means of the self-administered baseline questionnaire. Three psychological strain variables were examined (ie, job satisfaction, emotional exhaustion, and sleeping difficulties). Job satisfaction was assessed by means of two questions, one on job task enjoyment (19) and the other on the general opinion about the job (20). Emotional exhaustion was measured according to a 7 item subscale of the Dutch version of the Maslach burnout inventory $(8,21)$. In our study one original item of this scale was omitted because it applies only to people-oriented jobs. Sleeping difficulties were assessed according to a 3-item scale (11). The psychometric properties and the construction of the scales for quantitative job demands, decision authority, skill discretion, supervisory support, co-worker support, and emotional 
exhaustion have been described by De Jonge et al (13), based on data from the present study.

The individual factors that were considered to be potential confounders (ie, age, gender, smoking habits, body mass index, exercise behavior and coping skills) were mainly assessed by means of the self-administered questionnaire. One question was included for the assessment of exercise behavior during leisure time (22). Coping skills (ie, active problem solving, avoidance behavior, and social support seeking) were assessed by means of the Utrecht coping list (23). The assessment of the body mass index was based on measurements of weight and height taken by a physiotherapist during the physical examination at the beginning of the study.

The work-related physical factors that were considered to be potential confounders were trunk flexion, lifting, and driving a vehicle at work. The percentage of the worktime spent with the trunk in a minimum of 30 or 60 degrees of flexion and the number of times workers lifted a load of any weight, or a load of at least 10 or 25 kilograms during a workday, were assessed by means of analyses of video-recordings and force measurements at the workplace. These measurements have been described in more detail elsewhere (14). Driving a vehicle at work was assessed by means of the Loquest questionnaire (24).

In the initial and follow-up questionnaires, the assessment of the occurrence of low-back pain was based on an adaptation of a Nordic questionnaire (25). The workers had to answer the question "Have you, in the previous 12 months, had trouble (ache, pain, discomfort) in the low back?" with one of the following four options: no, never; yes, sometimes; yes, regularly; yes, prolonged. Cases of low-back pain were defined as workers who reported, for at least one of the follow-up measurements, that they had had regular or prolonged low-back pain in the previous 12 months.

\section{Statistical analysis}

The statistical analysis consisted of several steps. Univariate analyses were performed with the computer package Epi Info (version 6.0). In these analyses, the various scales for psychosocial work characteristics were recoded as categorical variables using small intervals on the measurement scale of the variable to determine the relationship with low-back pain. In general, small categories with similar relative risks were regrouped into a few larger categories that resulted in division into three categories (low, medium, high). Relative risks (RR) and corresponding 95\% confidence intervals $(95 \% \mathrm{CI})$ were calculated for the psychosocial work characteristics under study by comparing the cumulative incidence of low-back pain between groups with different levels of exposure. If the individual fac- tors, work-related physical factors, and other factors (job security) that were considered to be potential confounders were univariately associated with the occurrence of low-back pain with a Yates' corrected P-value (26) of less than 0.25 (27), they were included in the multivariate analyses. However, age, gender, and the other psychosocial work characteristics under study were included in the multivariate analyses irrespective of their univariate association with low-back pain in this data set. For the psychosocial work characteristics, this decision was based on the fact that these variables are related.

The presence of confounding was assessed by means of multivariate analyses. To prevent the occurrence of collinearity, the degree of interrelationship between the psychosocial work characteristics under study and the other independent variables selected for the multivariate analyses was first checked. The Cox regression procedure in the SPSS (Statistical Package for the Social Sciences) computer package (version 9.0) was applied for the estimation of adjusted relative risks, using a constant risk period for all the subjects (28-30). The adjusted relative risks were determined in a full model with one of the psychosocial work characteristics, the individual factors, other psychosocial work characteristics, and work-related physical factors that were selected on the basis of the results of the univariate analyses. To determine whether adjustment for the potential confounders influenced the results, we checked whether the effect estimates for the psychosocial work characteristics included in the full model differed by more than $10 \%$ from the crude effect estimates. A stepwise procedure was used to construct the full model. This made it possible to determine whether the results were mainly influenced by adjustment for the group of individual factors, the group of other psychosocial work characteristics, or the group of work-related physical factors.

The described multivariate analyses were repeated for the workers who reported that no, or only minor, changes in their work had occurred during the first and second follow-up periods. This selection reduced the likelihood of misclassification of exposure resulting from changes in the work environment over time. Participants whose work had changed due to back pain were also included in these analyses, because excluding them could have resulted in a false decrease in the effect estimates. Moreover, to determine the presence or absence of a healthy worker effect, the analyses were also repeated for the workers who had been employed in their current job for 5 years or less at baseline.

Furthermore, to investigate the intermediate role of the psychological strain variables of job satisfaction, emotional exhaustion, and sleeping difficulties in the relationship between psychosocial work characteristics and low-back pain, we added these variables to the full multivariate model one at a time. With these analyses 
we were able to evaluate the effect of the psychological strain variables on low-back pain with adjustment for the psychosocial work characteristics under study and the potential confounders $(31,32)$. The degree of change in the effect estimates for the psychosocial work characteristics could also be evaluated $(31,32)$. If the effect estimates for the psychosocial work characteristics decreased by more than $10 \%$ after a psychological strain variable was included, the existence of an intermediate role for this variable was considered to be likely.

\section{Results}

From the cohort of 1192 workers, data on the occurrence of low-back pain were available for 861 workers $(72 \%)$ for all three annual follow-up measurements. Approximately $30 \%$ of the workers in this group were female. The mean age of the workers was 36 years, with an age range of 18-59 years. The cumulative incidence of low-back pain during the three-year follow-up period was $26.6 \%$.

\section{Crude relationships}

Table 1 presents the results of the univariate analyses of the relationship between the psychosocial work characteristics and low-back pain. The strongest relationships with low-back pain were found for high quantitative job demands, low supervisory support, and low coworker support, followed by high conflicting demands and low skill discretion. Most of the relationships were not, or were only marginally, statistically significant. Decision authority was not found to be related to lowback pain.

\section{Potential confounders of the studied relationships}

Univariate analyses of the potential confounders showed that exercise behavior during leisure time, active problem solving, avoidance behavior, social support seeking, trunk flexion, lifting, and driving a vehicle at work were univariately associated with low-back pain with a $\mathrm{P}$-value of less than 0.25 . Therefore, these variables were included in the multivariate analyses of the psychosocial work characteristics under study. It was decided beforehand to include age, gender, and the other psychosocial work characteristics under study, independent of their association with low-back pain.

The multivariate analyses of the relationship between the psychosocial work characteristics and lowback pain showed that only the relative risk for low skill discretion changed by more than $10 \%$ after adjustment

for the variables that were selected (table 2). The decrease in the estimated relative risk for low supervisory support was slightly less than $10 \%$. The changes in the estimated relative risks were mainly caused by adjustment for the other psychosocial work characteristics. In the case of supervisory support, the adjustment for co-worker support appeared to be especially important.

\section{Change in work}

In the subgroup of workers who reported that no, or only minor, changes in their work had occurred, the adjusted relative risks for high quantitative job demands and medium and low supervisory support were slightly higher in comparison with the relative risks for the complete cohort. No difference was observed in the relative risks for conflicting demands, decision authority, skill discretion, or co-worker support (table 2).

\section{Healthy worker effect}

In the subgroup of workers who reported that they had been working in their current job for 5 years or less at the beginning of the study, the adjusted relative risks for medium and high quantitative job demands were substantially higher than in the complete cohort. The crude relative risk for high quantitative job demands was even higher (RR 3.0, 95\% CI 1.2-7.4). The change in

Table 1. Crude relationship between psychosocial work characteristics and the occurrence of low-back pain (LBP). (RR = relative risk, $95 \% \mathrm{Cl}=95 \%$ confidence interval)

\begin{tabular}{lrrrc}
\hline Risk factor & LBP & No LBP & Crude RR & $95 \% \mathrm{Cl}$ \\
\hline Quantitative job demands & & & & \\
$\quad$ Low (score 6-11) & 55 & 192 & 1.00 &.. \\
$\quad$ Medium (score 12-16) & 156 & 405 & 1.25 & $0.95-1.63$ \\
$\quad$ High (score 17-20) & 18 & 34 & 1.55 & $1.00-2.41$ \\
Conflicting demands & & & & \\
$\quad$ Disagree (strongly) & 152 & 437 & 1.00 &.. \\
$\quad$ Agree & 56 & 152 & 1.04 & $0.80-1.36$ \\
$\quad$ Strongly agree & 20 & 39 & 1.31 & $0.90-1.92$ \\
Decision authority & & & & \\
$\quad$ High (score 10-12) & 48 & 140 & 1.00 &.. \\
$\quad$ Medium (score 7-9) & 150 & 404 & 1.06 & $0.80-1.40$ \\
$\quad$ Low (score 3-6) & 29 & 84 & 1.01 & $0.68-1.50$ \\
Skill discretion & & & & \\
$\quad$ High (score 17-20) & 51 & 151 & 1.00 &.. \\
$\quad$ Medium (score 12-16) & 152 & 425 & 1.04 & $0.79-1.37$ \\
$\quad$ Low (score 5-11) & 26 & 56 & 1.26 & $0.84-1.87$ \\
Supervisory support & & & & \\
$\quad$ High (score 13-16) & 23 & 86 & 1.00 &.. \\
$\quad$ Medium (score 11-12) & 127 & 368 & 1.22 & $0.82-1.80$ \\
$\quad$ Low (score 4-10) & 79 & 176 & 1.47 & $0.98-2.20$ \\
Co-worker support & & & & \\
$\quad$ High (score 13-16) & 39 & 150 & 1.00 & \\
$\quad$ Medium (score 11-12) & 164 & 421 & 1.36 & $1.00-1.85$ \\
$\quad$ Low (score 4-10) & 25 & 57 & 1.48 & $0.96-2.27$ \\
\hline & & & & \\
\hline
\end{tabular}


Table 2. Results from the multivariate analyses for the relationship between psychosocial work characteristics and the occurrence of low-back pain. (RR = relative risk, $95 \% \mathrm{Cl}=95 \%$ confidence interval.)

\begin{tabular}{|c|c|c|c|c|c|c|c|c|}
\hline \multirow[t]{2}{*}{ Risk factor } & \multirow[t]{2}{*}{$\begin{array}{l}\text { Crude } \\
\text { RR }^{\mathrm{a}, \mathrm{b}}\end{array}$} & \multirow[t]{2}{*}{$\begin{array}{l}95 \% \mathrm{Cl} \\
\text { of the } \\
\text { crude } \\
\mathrm{RR}\end{array}$} & \multirow[t]{2}{*}{$\begin{array}{l}\text { Adjusted } \\
\mathrm{RR}^{\mathrm{b}, \mathrm{c}}\end{array}$} & \multirow[t]{2}{*}{$\begin{array}{l}95 \% \mathrm{Cl} \\
\text { of the } \\
\text { adjusted } \\
\mathrm{RR}\end{array}$} & \multicolumn{2}{|c|}{$\begin{array}{l}\text { Workers with no or only } \\
\text { minor changes in work } \\
(\mathrm{N}=669)\end{array}$} & \multicolumn{2}{|c|}{$\begin{array}{l}\text { Workers employed for } \leq 5 \text { years } \\
\text { in the current job at baseline } \\
(\mathrm{N}=334)\end{array}$} \\
\hline & & & & & Adjusted RR ${ }^{c}$ & $95 \% \mathrm{Cl}$ & Adjusted $\mathrm{RR}^{\mathrm{c}}$ & $95 \% \mathrm{Cl}$ \\
\hline \multicolumn{9}{|l|}{ Quantitative job demands } \\
\hline Low (score 6-11) & 1.00 & & 1.00 & .. & 1.00 & & 1.00 & \\
\hline Medium (score 12-16) & 1.27 & $0.92-1.75$ & 1.24 & $0.89-1.71$ & 1.31 & $0.91-1.89$ & 2.11 & $1.17-3.81$ \\
\hline High (score 17-20) & 1.52 & $0.84-2.75$ & 1.41 & $0.76-2.62$ & 1.56 & $0.81-3.03$ & 2.49 & $0.92-6.74$ \\
\hline \multicolumn{9}{|l|}{ Conflicting demands } \\
\hline Disagree (strongly ) & 1.00 & .. & 1.00 & .. & 1.00 & .. & 1.00 & .. \\
\hline Agree & 1.04 & $0.75-1.43$ & 1.02 & $0.73-1.43$ & 1.09 & $0.76-1.56$ & 0.96 & $0.56-1.67$ \\
\hline Strongly agree & 1.32 & $0.80-2.18$ & 1.37 & $0.81-2.32$ & 1.34 & $0.75-2.39$ & 1.33 & $0.52-3.37$ \\
\hline \multicolumn{9}{|l|}{ Decision authority } \\
\hline High (score $10-12$ ) & 1.00 & .. & 1.00 & .. & 1.00 & .. & 1.00 & .. \\
\hline Medium (score 7-9) & 1.03 & $0.73-1.44$ & 0.98 & $0.66-1.45$ & 1.00 & $0.65-1.54$ & 0.88 & $0.45-1.71$ \\
\hline Low (score 3-6) & 1.05 & $0.65-1.68$ & 0.98 & $0.56-1.71$ & 0.99 & $0.54-1.80$ & 1.00 & $0.43-2.33$ \\
\hline \multicolumn{9}{|l|}{ Skill discretion } \\
\hline High (score 17-20) & 1.00 & .. & 1.00 & .. & 1.00 & .. & 1.00 & \\
\hline Medium (score 12-16) & 1.02 & $0.73-1.42$ & 1.00 & $0.67-1.49$ & 1.00 & $0.65-1.55$ & 1.13 & $0.58-2.18$ \\
\hline Low (score 5-11) & 1.22 & $0.74-2.00$ & 0.97 & $0.53-1.75$ & 0.85 & $0.44-1.66$ & 1.01 & $0.41-2.44$ \\
\hline \multicolumn{9}{|l|}{ Supervisory support } \\
\hline High (score 13-16) & 1.00 & .. & 1.00 & .. & 1.00 & .. & 1.00 & . \\
\hline Medium (score 11,12) & 1.29 & $0.82-2.03$ & 1.25 & $0.75-2.07$ & 1.41 & $0.79-2.50$ & 1.75 & $0.78-3.95$ \\
\hline Low (score 4-10) & 1.43 & $0.89-2.32$ & 1.29 & $0.76-2.21$ & 1.41 & $0.77-2.60$ & 1.88 & $0.76-4.64$ \\
\hline \multicolumn{9}{|l|}{ Co-worker support } \\
\hline High (score 13-16) & 1.00 & & 1.00 & $"$ & 1.00 & & 1.00 & \\
\hline Medium (score 11-12) & 1.30 & $0.90-1.86$ & 1.35 & $0.90-2.02$ & 1.20 & $0.79-1.83$ & 1.33 & $0.74-2.41$ \\
\hline Low (score 4-10) & 1.54 & $0.92-2.59$ & 1.65 & $0.92-2.95$ & 1.68 & $0.90-3.14$ & 1.32 & $0.56-3.13$ \\
\hline
\end{tabular}

a Crude relative risk from the Cox regression for the population with no missing values for gender, age, exercise behavior during leisure time, active problem solving, avoidance behavior, social support seeking, trunk flexion, lifting, driving a vehicle at work, and the other psychosocial work characteristics mentioned in the table.

${ }^{\mathrm{b}}$ Number of workers $=768$.

c Relative risk from the Cox regression, adjusted for the risk factors mentioned in footnote a.

Table 3. Relationship of job satisfaction, emotional exhaustion and sleeping difficulties with low-back pain (LBP). ( $R R=$ relative risk, $95 \% \mathrm{Cl}=95 \%$ confidence interval)

\begin{tabular}{|c|c|c|c|c|}
\hline Risk factor & LBP & No LBP & Adjusted RR ${ }^{a}$ & $95 \% \mathrm{Cl}$ \\
\hline \multicolumn{5}{|l|}{ Job task enjoyment } \\
\hline Always (almost) & 110 & 337 & 1.00 & .. \\
\hline Often & 96 & 240 & 1.13 & $0.83-1.54$ \\
\hline Never or sometimes & 23 & 55 & 1.28 & $0.77-2.14$ \\
\hline \multicolumn{5}{|l|}{$\begin{array}{l}\text { Job satisfaction, general } \\
\text { opinion about the job }\end{array}$} \\
\hline Good & 117 & 412 & 1.00 & .. \\
\hline Reasonable & 98 & 197 & 1.54 & $1.14-2.08$ \\
\hline Not good or moderate & 14 & 22 & 1.75 & $0.96-3.19$ \\
\hline \multicolumn{5}{|l|}{ Emotional exhaustion } \\
\hline Score 0 & 99 & 333 & 1.00 & .. \\
\hline Score 1 & 59 & 151 & 1.12 & $0.79-1.59$ \\
\hline Score 2, 3 & 48 & 112 & 1.15 & $0.78-1.70$ \\
\hline Score $4-7$ & 23 & 32 & 1.70 & $1.03-2.81$ \\
\hline \multicolumn{5}{|l|}{ Sleeping difficulties } \\
\hline Score 0 & 152 & 482 & 1.00 & 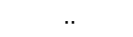 \\
\hline Score 1 & 41 & 95 & 1.29 & $0.88-1.88$ \\
\hline Score 2 & 20 & 30 & 1.64 & $1.00-2.68$ \\
\hline Score 3 & 8 & 9 & 2.14 & $0.98-4.64$ \\
\hline
\end{tabular}

the estimated relative risk was mainly caused by the adjustment for work-related physical factors. The relative risks for medium and low supervisory support were also substantially higher in this subgroup than in the complete cohort. The relative risk for low co-worker support was slightly lower than in the complete cohort. Univariately, the relative risk for low co-worker support was still higher. The decrease in the estimated relative risk for low co-worker support was mainly caused by the adjustment for supervisory support. No difference was observed in the relative risks for conflicting demands, decision authority, or skill discretion (table 2).

\section{Role of the psychological strain variables}

Tables 3 and 4 show the results of the multivariate analyses for the relationship between psychosocial work characteristics and low-back pain with the inclusion of the psychological strain variables. It can be seen from table 3 that a statistically significant increased risk was observed for low-back pain among workers whose opinion about their job in general was less than good, among workers with a high score on the scale for emotional 
Table 4. Results from the multivariate analyses for the relationship between psychosocial work characteristics and low-back pain with the inclusion of potential intermediate variables. ( $\mathrm{RR}=$ relative risk, $95 \% \mathrm{Cl}=95 \%$ confidence interval)

\begin{tabular}{|c|c|c|c|c|c|c|c|c|c|c|}
\hline \multirow[t]{2}{*}{ Risk factor } & \multicolumn{2}{|c|}{ Adjusted $\mathrm{a,b}$} & \multicolumn{2}{|c|}{$\begin{array}{l}\text { After additional } \\
\text { adjustment for } \\
\text { job task enjoyment }{ }^{b}\end{array}$} & \multicolumn{2}{|c|}{$\begin{array}{l}\text { After additional } \\
\text { adjustment for } \\
\text { general opinion } \\
\text { about the job }{ }^{c}\end{array}$} & \multicolumn{2}{|c|}{$\begin{array}{l}\text { After additional } \\
\text { adjustment for } \\
\text { emotional exhaustion }{ }^{\mathrm{d}}\end{array}$} & \multicolumn{2}{|c|}{$\begin{array}{l}\text { After additional } \\
\text { adjustment for } \\
\text { sleeping difficulties }\end{array}$} \\
\hline & $\mathrm{RR}$ & $95 \% \mathrm{Cl}$ & $\mathrm{RR}$ & $95 \% \mathrm{Cl}$ & $\mathrm{RR}$ & $95 \% \mathrm{Cl}$ & $\mathrm{RR}$ & $95 \% \mathrm{Cl}$ & $\mathrm{RR}$ & $95 \% \mathrm{Cl}$ \\
\hline \multicolumn{11}{|l|}{ Quantitative job demands } \\
\hline $\begin{array}{l}\text { Low (score 6-11) } \\
\text { Medium (score 12-16) } \\
\text { High (score 17-20) }\end{array}$ & $\begin{array}{l}1.00 \\
1.24 \\
1.41\end{array}$ & $\begin{array}{l}0.89-1.71 \\
0.76-2.62\end{array}$ & $\begin{array}{l}1.00 \\
1.24 \\
1.40\end{array}$ & $\begin{array}{l}0.89-1.72 \\
0.75-2.60\end{array}$ & $\begin{array}{l}1.00 \\
1.22 \\
1.26\end{array}$ & $\begin{array}{c}. . \\
0.88-1.70 \\
0.67-2.36\end{array}$ & $\begin{array}{l}1.00 \\
1.18 \\
1.19\end{array}$ & $\begin{array}{l}0.85-1.65 \\
0.62-2.29\end{array}$ & $\begin{array}{l}1.00 \\
1.21 \\
1.42\end{array}$ & $\begin{array}{l}0.87-1.69 \\
0.76-2.66\end{array}$ \\
\hline \multicolumn{11}{|l|}{ Conflicting demands } \\
\hline $\begin{array}{l}\text { Disagree (strongly ) } \\
\text { Agree } \\
\text { Strongly agree }\end{array}$ & $\begin{array}{l}1.00 \\
1.02 \\
1.37\end{array}$ & $\begin{array}{c}. . \\
0.73-1.43 \\
0.81-2.32\end{array}$ & $\begin{array}{l}1.00 \\
1.02 \\
1.37\end{array}$ & $\begin{array}{c}. \cdot \\
0.73-1.42 \\
0.81-2.33\end{array}$ & $\begin{array}{l}1.00 \\
1.01 \\
1.40\end{array}$ & $\begin{array}{c}. . \\
0.72-1.41 \\
0.82-2.38\end{array}$ & $\begin{array}{l}1.00 \\
1.02 \\
1.33\end{array}$ & $\begin{array}{l}0.73-1.42 \\
0.78-2.27\end{array}$ & $\begin{array}{l}1.00 \\
1.01 \\
1.35\end{array}$ & $\begin{array}{l}. . \\
0.72-1.42 \\
0.79-2.30\end{array}$ \\
\hline \multicolumn{11}{|l|}{ Supervisory support } \\
\hline $\begin{array}{l}\text { High (score 13-16) } \\
\text { Medium (score 11-12) } \\
\text { Low (score 4-10) }\end{array}$ & $\begin{array}{l}1.00 \\
1.25 \\
1.29\end{array}$ & $\begin{array}{c}. . \\
0.75-2.07 \\
0.76-2.21\end{array}$ & $\begin{array}{l}1.00 \\
1.23 \\
1.25\end{array}$ & $\begin{array}{c}. . \\
0.74-2.04 \\
0.73-2.15\end{array}$ & $\begin{array}{l}1.00 \\
1.23 \\
1.17\end{array}$ & $\begin{array}{c}. . \\
0.74-2.05 \\
0.68-2.02\end{array}$ & $\begin{array}{l}1.00 \\
1.25 \\
1.23\end{array}$ & $\begin{array}{c}. . \\
0.75-2.06 \\
0.72-2.11\end{array}$ & $\begin{array}{l}1.00 \\
1.26 \\
1.30\end{array}$ & $\begin{array}{c}. . \\
0.75-2.11 \\
0.75-2.26\end{array}$ \\
\hline \multicolumn{11}{|l|}{ Co-worker support } \\
\hline $\begin{array}{l}\text { High (score 13-16) } \\
\text { Medium (score 11-12) } \\
\text { Low (score 4-10) }\end{array}$ & $\begin{array}{l}1.00 \\
1.35 \\
1.65\end{array}$ & $\begin{array}{c}. \ddot{ } \\
0.90-2.02 \\
0.92-2.95\end{array}$ & $\begin{array}{l}1.00 \\
1.34 \\
1.60\end{array}$ & $\begin{array}{c}. \cdot \\
0.90-2.01 \\
0.89-2.88\end{array}$ & $\begin{array}{l}1.00 \\
1.33 \\
1.56\end{array}$ & $\begin{array}{c}. . \\
0.89-1.99 \\
0.87-2.81\end{array}$ & $\begin{array}{l}1.00 \\
1.35 \\
1.60\end{array}$ & $\begin{array}{c}. \cdot \\
0.90-2.01 \\
0.89-2.86\end{array}$ & $\begin{array}{l}1.00 \\
1.36 \\
1.59\end{array}$ & $\begin{array}{c}. . \\
0.91-2.04 \\
0.89-2.86\end{array}$ \\
\hline
\end{tabular}

a Relative risk from the Cox regression, adjusted for gender, age, exercise behavior during leisure time, active problem solving, avoidance behavior, social support seeking, trunk flexion, lifting, driving a vehicle at work, decision authority, skill discretion, and the other psychosocial work characteristics mentioned in the table.

b Number of persons $=768$.

c Number of persons $=767$.

${ }^{\mathrm{d}}$ Number of persons $=766$.

e Number of persons $=762$

exhaustion, and among workers with a high score on the scale for sleeping difficulties. No statistically significant increased risk was found for workers who reported that they never, or only sometimes, enjoyed their job tasks.

It can be seen from table 4 that, in general, the estimated relative risks for the psychosocial work characteristics were scarcely influenced by adjustment for the psychological strain variables. Only the estimated relative risk for high quantitative job demands decreased by more than $10 \%$ after additional adjustment for the variable of general opinion about the job and after additional adjustment for emotional exhaustion. Therefore, an intermediate role of the psychological strain variables was not considered to be likely, at least not for the effect of conflicting demands, supervisory support, and co-worker support. The psychosocial work characteristics of decision authority and skill discretion are not included in table 4 because no relationship was observed between these factors and low-back pain, which is one of the conditions that must be met if an intermediate variable is to fulfill its role $(31,32)$.

\section{Discussion}

\section{Summary of findings}

The multivariate analyses showed that, in the complete cohort and in the subgroup of workers with no, or only minor, changes in their work, there was a 1.3- to 1.6fold increased risk of low-back pain for workers with high quantitative job demands, for workers with high conflicting demands, for workers with low supervisory support, and for workers with low co-worker support. The adjusted relative risks for the relationships found were not, or were only borderline, statistically significant. This result was partly due to the use of the Cox regression, which produces estimates of the standard errors that are too large and that result in estimates of the confidence intervals that are too conservative (29, 30). No relationship with low-back pain was found for low decision authority or low skill discretion.

An important source of potential bias in occupational cohort studies is the healthy worker effect (33). For this form of bias to be minimized, it would have been better to study newly employed workers, but such an approach was beyond the scope of our study. Therefore, an additional analysis of the group of workers who had been employed in their current job for 5 years or less was performed. This analysis showed stronger associations with low-back pain for medium and high quantitative job demands and for medium and low supervisory support. Moreover, a weaker association was found for low co-worker support. These results may indicate the presence of a healthy worker effect in the complete cohort. The results for supervisory support and co-worker support might also indicate that different types of support could be important during different stages of employment. 
The results of the analyses with additional adjustment for a psychological strain variable do not indicate that the psychological strain variables of job satisfaction, emotional exhaustion, and sleeping difficulties are intermediates in the relationship between high conflicting demands, supervisory support, and co-worker support and low-back pain. The general opinion about the job and emotional exhaustion may be intermediates in the relationship between high quantitative job demands and low-back pain. For a variable to be considered an intermediate variable, several conditions must be met $(31,32)$. Previous analyses of the data from our study have shown that there is a relationship between the psychosocial work characteristics of high job demands, low supervisory support, and low co-worker support and the psychological strain variables of job task enjoyment and emotional exhaustion (13). In our analyses, the psychological strain variables themselves, except for the operationalization of job satisfaction in terms of job task enjoyment, were statistically significantly associated with low-back pain and are therefore independent risk factors for the occurrence of low-back pain. The assessment of the influence of additional adjustment for the psychological strain variables on the effect estimates for the psychosocial work characteristics was complicated, due to the small magnitude of the observed effects for the psychosocial work characteristics.

The results of this study do not support the hypothesis that the association between psychosocial work characteristics and low-back pain is based on confounding by the effect of physical factors at work. Adjustment for work-related physical factors had scarcely any effect on the estimated relative risks in the complete cohort. However, again, no strong conclusions can be based on this observation due to the small magnitude of the observed effects for the psychosocial work characteristics. In the subgroup of workers who had been employed in their current job for 5 years or less at the beginning of the study, a stronger crude effect was observed for high quantitative job demands. Adjustment for work-related physical factors appeared to affect the magnitude of this effect. This result suggests that part of the crude association was due to an association between high physical load and high job demands in this subgroup. However, a statistically significant relative risk remained.

\section{Methodological strengths and limitations}

The prospective design of our study made it possible to take into consideration the temporal relationship between psychosocial work characteristics and low-back pain. Moreover, in addition to adjustment for individual factors and other psychosocial work characteristics, a thorough adjustment for work-related physical factors was possible, on the basis of actual quantification of the physical load at the workplace. Both aspects strengthen the concept that the associations that were found may be causal relationships.

The possibility of bias due to selective loss to follow-up cannot be excluded. In this study the percentage of workers in the reference category of conflicting demands was lower in the group that was lost to follow-up. Relatively more workers in this group reported low decision authority and low skill discretion (data not shown). This finding is probably related to the fact that the group that was lost to follow-up had a relatively low level of education (data not shown). However, no selectivity in the loss to follow-up was found with respect to quantitative job demands, supervisory support, or coworker support.

Due to the selection of workers with no low-back pain at the beginning of the study and the necessity to have data on the occurrence of low-back pain for all the follow-up measurements, a relatively small proportion of the original cohort of 1738 workers was included in the present analyses. As a result, the statistical power to detect weak associations (relative risk in the order of 1.5) was limited.

In this study, it was decided to use a cumulative measure of the occurrence of low-back pain over the 3year follow-up period. Therefore, the course of lowback pain over the follow-up period was not taken into account in these analyses. Further analyses could be performed to study more specifically the influence of psychosocial work characteristics on the course of lowback pain.

\section{Comparison with previous findings}

Due to the small magnitude of the observed effects for the psychosocial work characteristics and the lack of clearly statistically significant effects, it is difficult to draw firm conclusions based on our results. Therefore, comparison of the findings with previous findings is especially important. Of special interest is the comparison of our results with those of other cohort studies that were restricted to a population with no low-back pain at the beginning of the study and case-referent studies that excluded subjects with low-back pain in the previous months from enrollment. The findings of various studies investigating the risk of high quantitative job demands are inconsistent. One study, the MUSIC study, reported no effect of high quantitative job demands on care seeking for low-back pain among nursing personnel (34), one study only reported that no statistically significant association was found (35) and one reported an increased risk of sciatic pain (36), in agreement with the our results. 
One other prospective cohort study, the Whitehall study, examined the effect of conflicting demands (37). However, this study was not restricted to subjects with no low-back pain at the beginning of the study, and it focused on the occurrence of absenteeism from work due to back pain. It was found that conflicting demands were only a risk factor for short absences from work due to back pain among men. An additional exploratory analysis of the data from our study also showed that the risk of low-back pain due to conflicting demands seems to be stronger among the men than among the complete cohort (data not shown).

With regard to decision authority and skill discretion, the MUSIC study reported that no effect on care seeking for low-back pain was found among a subcohort of nursing personnel (34). However, the analyses of the total population of this study showed that low skill discretion was associated with care seeking for low-back pain among men (38). Another study only reported that no statistically significant association was found between skill discretion and low-back pain (35).

Three studies have examined the effect of social support, a combination of supervisory and co-worker support $(34,36,38,39)$ These studies all reported an increased risk of low-back pain for low social support (34, 36, 39), except for the total population of the MUSIC study (38). Two prospective cohort studies that were not restricted to a population with no low-back pain at the beginning of the study examined the individual effects of supervisory and co-worker support $(19,40)$. One study found an effect of both supervisory and co-worker support (19), and the other found an effect of low supervisory support and no effect of co-worker support (40). However, the fact that low supervisory support, as opposed to low co-worker support, was especially important in the latter study may be related to the nature of the job of transit operators (40). On the basis of the main analyses of our study, co-worker support seems to be more important than supervisory support. However, in the subgroup of workers who had been employed in their current job for 5 years or less at the beginning of the study, the relative importance was reversed. Although it remains to be seen whether supervisory support and co-worker support are equally important, it is clear that far more consistent results have been found for low social support than for the other psychosocial work characteristics. This trend is also reported in a recent review on the relationship between psychosocial work characteristics and low-back pain (4). The magnitude of the observed relative risks in our study also lies in the range of observed risk estimates for previous studies as reported in this review (4).

The authors are not aware of any other study that has examined the potential intermediate role of psychological strain variables with methods similar to those used in our study. However, the direct effect of job dissatisfaction has been studied extensively. In these studies job dissatisfaction has always been considered to pertain to the group of psychosocial work characteristics. Various studies have reported an increased risk of low-back pain in relation to low job satisfaction $(35,37$, 39). From our study, it appears that, if an effect of job dissatisfaction does exist, it is probably independent of the effect of psychosocial work characteristics. An effect of low job satisfaction was found for only one of the two measures of job satisfaction that were used, but this result may be explained by the presence of selectivity in the loss to follow-up with respect to job task enjoyment (data not shown).

\section{Concluding remarks}

Whereas only moderate, and not statistically significant, associations were found between low supervisory and low co-worker support and the occurrence of low-back pain, on the basis of the comparison with previous findings, it seems likely that low social support is, indeed, a risk factor for the occurrence of low-back pain. According to the results of our study, some indications of a relationship between high quantitative job demands and high conflicting demands and low-back pain are also present. However, the relationship between these variables and low-back pain has not been observed consistently in other studies. In our study, no relationship was observed between low decision authority or low skill discretion and the occurrence of low-back pain.

The results of this study do not support the hypothesis that the psychological strain variables of job satisfaction, emotional exhaustion, and sleeping difficulties play an intermediate role in the relationship between conflicting demands, supervisory support, and co-worker support and low-back pain. The general opinion about the job and emotional exhaustion may be intermediates in the relationship between high quantitative job demands and low-back pain. However, it is not possible to draw strong conclusions with respect to this subject because our study is the first to examine this hypothesis. In addition, the small magnitude of the observed effects for the psychosocial work characteristics complicated the examination of the potential intermediate role of the psychological strain variables.

\section{Acknowledgments}

This study was financially supported by the Dutch Ministry of Social Affairs and Employment, the Dutch Ministry of Public Health, Welfare and Sports, and the Dutch National Institute for Social Security. 


\section{References}

1. Bongers PM, Winter CR de, Kompier MA, Hildebrandt VH. Psychosocial factors at work and musculoskeletal disease [review]. Scand J Work Environ Health 1993;19:297-312.

2. Bernard BP, editor. Musculoskeletal disorders and workplace factors: a critical review of epidemiologic evidence for workrelated musculoskeletal disorders of the neck, upper extremity, and low back. Cincinnati $(\mathrm{OH})$ : National Institute for Occupational Safety and Health, US Department of Health and Human Services, 1997.

3. Burdorf A, Sorock G. Positive and negative evidence of risk factors for back disorders [review]. Scand J Work Environ Health 1997;23:243-56.

4. Hoogendoorn WE, Poppel MNM van, Bongers PM, Koes BW, Bouter LM. Systematic review of psychosocial factors at work and in private life as risk factors for back pain. Spine 2000;25:2114-25.

5. Davis KG, Heaney CA. The relationship between psychosocial work characteristics and low back pain: underlying methodological issues [review]. Clin Biomech 2000;15:389—406.

6. Sauter SL, Swanson NG. An ecological model of musculoskeletal disorders in office work. In: Moon SD, Sauter SL, editors. Beyond Biometrics: psychosocial aspects of musculoskeletal disorders in office work. London: Taylor \& Frances, 1996:3-21.

7. Theorell T. How to deal with stress in organizations? - a health perspective on theory and practice. Scand J Work Environ Health 1999;25:616-24.

8. Maslach C, Jackson SE. Maslach Burnout Inventory: manual. 2nd ed. Palo Alto (CA): Consulting Psychologists Press, 1996.

9. Lindberg U, Johansson G. Stress and health risks in repetitive work and supervisory monitoring work. In: Backs R, Boucsein W, editors. Engineering psychophysiology: issues and applications. Hillsdale (NJ): Lawrence Erlbaum Assoc, 1999:339-59.

10. Westgaard RH. Effects of physical and mental stressors on muscle pain. Scand J Work Environ Health 1999;25 suppl 4:19-24.

11. Appels A, Schouten E. Waking up exhausted as risk indicator of myocardial exhaustion. Am J Cardiol 1991;68:395-8.

12. Amick BC, Swanson NG, Chang H. Office technology and musculoskeletal disorders: building an ecological model. Occup Med 1999;14:97-112.

13. Jonge $\mathrm{J}$ de, Reuvers MMEN, Houtman ILD, Bongers PM, Kompier MAJ. Linear and nonlinear relations between psychosocial job characteristics, subjective outcomes, and sickness absence: baseline results from SMASH. J Occup Health Psychol 2000;5:256-68.

14. Hoogendoorn WE, Bongers PM, Vet HCW de, Douwes M, Koes BW, Miedema MC et al. Flexion and rotation of the trunk and lifting at work are risk factors for low back pain: results of a prospective cohort study. Spine 2000;25:308792.

15. Karasek R. Job content instrument users guide: revision 1.1. Los Angeles (CA): Department of Industrial and Systems Engineering, University of Southern California, 1985.

16. Karasek RA. Job demands, job decision latitude, and mental strain: implications for job redesign. Admin Sci Q 1979;24: 285-308.

17. Johnson JV, Hall E. Job strain, work place social support, and cardiovascular disease. Am J Public Health 1988;78:133642.
18. Karasek RA, Theorell T. Healthy work: stress, productivity, and the reconstruction of working life. New York (NY): Basic Books, 1990.

19. Bigos SJ, Battié MC, Spengler DM, Fisher LD, Fordyce WE, Hansson TH, et al. A prospective study of work perceptions and psychosocial factors affecting the report of back injury [published erratum appears in Spine 1991;16:688]. Spine 1991;16:1-6.

20. Gründemann RWM, Smulders PGW, Winter CR de. Handleiding vragenlijst Arbeid en Gezondheid [Manual questionnaire work and health]. Lisse: Swets \& Zeitlinger, 1993.

21. Schaufeli WB, Dierendonck D van. The construct validity of two burnout measures. J Organ Behav 1993;14:631-47.

22. Godin G, Jobin J, Bouillon J. Assessment of leisure time exercise behavior by self-report: a concurrent validity study. Can J Public Health 1986;77:359-62.

23. Schreurs PJG, Willige G van der, Tellegen B, Brosschot JF. De Utrechtse Coping Lijst: UCL-handleiding [The Utrecht coping list: UCL-Manual]. Lisse: Swets \& Zeitlinger, 1988.

24. Hildebrandt VH, Douwes M. Lichamelijke belasting en arbeid: vragenlijst bewegingsapparaat [Physical load and work: questionnaire on musculoskeletal load and health complaints]. Voorburg: Ministry of Social Affairs and Employment, 1991: S122-3.

25. Kuorinka I, Jonsson B, Kilbom A, Vinterberg H, BieringSørensen F, Andersson G, et al. Standardised Nordic questionnaire for the analysis of musculoskeletal symptoms. Appl Ergon 1987;18:233-7.

26. Altman DG. Comparing groups - categorical data. In: Practical statistics for medical research. London: Chapman \& Hall, 1991:229-76.

27. Hosmer DW, Lemeshow S. Model-building strategies and methods for logistic regression. In: Applied logistic regression. New York: John Wiley \& Sons, 1989:82-134.

28. Lee J. Odds ratio or relative risk for cross-sectional data? Int J Epidemiol 1994;23:201-3.

29. Skov T, Deddens J, Petersen MR, Endahl L. Prevalence proportion ratios: estimation and hypothesis testing. Int $\mathrm{J}$ Epidemiol 1998;27:91-5.

30. Thompson ML, Myers JE, Kriebel D. Prevalence odds ratio or prevalence ratio in the analysis of cross-sectional data: what is to be done? Occup Environ Med 1998;55:272-7.

31. Baron RM, Kenny DA. The moderator-mediator variable distinction in social psychological research: conceptual, strategic, and statistical considerations. J Pers Soc Psychol 1986;51:1173-82.

32. Holmbeck GN. Toward terminological, conceptual, and statistical clarity in the study of mediators and moderators: examples from the child-clinical and pediatric psychology literatures. J Consult Clin Psychol 1997;65:599—610.

33. Checkoway H, Eisen EA. Developments in occupational cohort studies. Epidemiol Rev 1998;20:100—11.

34. Josephson M, Vingård E, MUSIC-Norrtälje Study Group. Workplace factors and care seeking for low-back pain among female nursing personnel. Scand J Work Environ Health 1998;24(6):465-72.

35. Biering-Sørensen F, Thomsen C. Medical, social and occupational history as risk indicators for low-back trouble in a general population. Spine 1986;11:720-5.

36. Riihimäki H, Viikari-Juntura E, Moneta G, Kuha J, Videman $\mathrm{T}$, Tola $\mathrm{S}$. Incidence of sciatic pain among men in machine operating, dynamic physical work, and sedentary work. a three-year follow-up. Spine 1994;19:138—42.

37. Hemingway H, Shipley MJ, Stansfeld S, Marmot M. Sick- 
ness absence from back pain, psychosocial work characteristics and employment grade among office workers. Scand J Work Environ Health 1997;23:121-9.

38. Vingård E, Alfredsson L, Hagberg M, Kilbom Å, Theorell T, Waldenström $\mathrm{M}$ et al. To what extent do current and past physical and psychosocial occupational factors explain careseeking for low back pain in a working population? Results from the musculoskeletal intervention center-Norrtälje Study. Spine 2000;25:493-500.

39. Papageorgiou AC, Macfarlane GJ, Thomas E, Croft PR, Jayson MI, Silman AJ. Psychosocial factors in the workplace - do they predict new episodes of low back pain? Evidence from the South Manchester Back Pain Study. Spine 1997;22:1137-42.

40. Krause N, Ragland DR, Fisher JM, Syme SL. Psychosocial job factors, physical workload, and incidence of work-related spinal injury: a 5-year prospective study of urban transit operators. Spine 1998;23:2507-16.

Received for publication: 3 October 2000 